\title{
Outcome Following Local Injection of A Liquid Amnion Allograft for Treatment of Equine Tendonitis or Desmitis - 100 Cases.
}

\section{Hugh R Duddy}

Oklahoma State University, College of VeterinaryMedicine

Mike J Schoonover ( $\square$ mjsdvm@gmail.com )

University of Oklahoma School of Community Medicine https://orcid.org/0000-0003-3723-0689

\section{Brent A Hague}

Oakridge Equine Hospital

Research article

Keywords: Regenerative medicine, horse, tendon, ligament

Posted Date: October 5th, 2020

DOI: https://doi.org/10.21203/rs.3.rs-55888/v1

License: (c) (i) This work is licensed under a Creative Commons Attribution 4.0 International License.

Read Full License 


\section{Abstract}

Background: Tendon and ligament injuries are significant causes of loss of use and early retirement in performance horses. Amniotic fluid and tissue are excellent sources of growth factors and cytokines important in tendon and ligament healing. Thus, a liquid amnion allograft (LAA) may be beneficial in the treatment of equine tendonitis and desmitis.

Objectives: Report the outcome achieved (i.e. ability to return to work) for horses diagnosed with tendonitis or desmitis lesions treated with local injection of LAA and to compare these outcomes to those reported for other regenerative medicine modalities.

Study design: Prospective, multi-center, non-blinded clinical trial.

Methods: Equine veterinarians at 14 sites were selected to participate in the data collection for the trial. Criterion for inclusion was a horse presenting with lameness which was attributed to tendonitis or desmitis by diagnostic anesthesia and/or imaging. These horses were subsequently treated by local injection of the lesion with LAA by the attending veterinarian. Standardized questionnaires describing each horse's signalmant, discipline, ability to return to work, and any adverse events were completed and submitted by the attending veterinarian following a minimum of six months follow-up.

Results: Questionnaires for 100 horses with 128 tendonitis and desmitis lesions met the inclusion criteria. Of these, 72 horses with 94 lesions returned to or exceeded their original level of work, 10 horses with 13 lesions returned to work but could not perform to previous standards, and 18 horses with 20 lesions did not return to work as a result of the injury. The attending veterinarian for 92 horses reported satisfaction with the LAA and the response to therapy. Adverse events following administration of LAA were reported in 13 horses.

Conclusions: Treatment of tendonitis and desmitis lesions by local injection of LAA achieves a similar rate of horses returning to previous level of performance as other regenerative modalities such as mesenchymal stem cells, platelet-rich plasma, and autologous conditioned serum; however, blinded placebo-controlled studies are indicated.

\section{Background}

Tendon and ligament injuries are a significant cause of morbidity in the performance horse and often compromise return to the previous level of activity. ${ }^{1-8}$ Healing of these injuries progresses through several sequential, overlapping phases. ${ }^{9,10}$ The initial response is the acute inflammatory phase characterized by pain, intra-lesional hemorrhage, and edema. Circulating inflammatory cells infiltrate the injury and release initial growth factors and cytokines. Growth factors and cytokines orchestrate biological processes throughout the healing process. ${ }^{1,9}$ The acute inflammatory response is followed by the proliferative phase where fibroblastic cells produce scar tissue comprised of far more type III collagen than the original tendon. $1,3,10,11$ The remodeling phase follows, resulting in the gradual transformation to 
more type I collagen though not to the same proportion as the original pre-injury tissue. ${ }^{1,3,10}$ The end result is a tendon that lacks pre-injury biomechanical properties. ${ }^{1,3,9,10}$

Regenerative medicine seeks to restore structure and function to injured tissue. ${ }^{12-14}$ The main components of regenerative therapies are scaffold, growth factors, and cells. ${ }^{12-14}$ Current therapies include mesenchymal stem cells (MSCs), platelet rich plasma (PRP), and autologous conditioned serum (ACS) ${ }^{7,10,12-18}$ Local injection of these therapies is common practice for horses with tendinous and ligamentous injuries. Amnion is considered a significant source of growth factors and cytokines important in tissue regeneration and healing. ${ }^{19,20}$ An equine origin, liquid amnion allograft (LAA) comprised of amnion and amniotic fluid is commercially available (RenoVo ${ }^{\text {TM }}$, Equus Innovations). Offthe-shelf availability of a regenerative modality could facilitate clinical use avoiding the time delay currently associated with autologous therapies that require sample collection and processing. To the authors' knowledge, no published studies evaluate LAA for the treatment of equine tendonitis or desmitis. The objective of this clinical trial was to evaluate the outcome (i.e. ability of horse to return to work) following local injection of LAA for the treatment of tendinitis and desmitis lesions. Additionally, these outcomes were to be compared to those reported in published clinical studies using regenerative modalities such as MSCs, PRP, ACS, and gene therapies for the treatment of tendonitis and desmitis. Our hypothesis was that treatment of specific equine tendonitis and desmitis lesions with local injection of LAA would result in outcomes comparable to horses with similar lesions treated with other regenerative modalities.

\section{Results}

Nineteen veterinarians submitted 170 questionnaires describing their experiences with LAA in horses. Following review, 100 questionnaires describing outcomes for 100 horses were determined to be complete and to have met the study's inclusion criteria; only these were included in the assessment (Table 1). A total of 128 tendonitis or desmitis lesions were described in these 100 questionnaires. Seventy-eight of the questionnaires described local injection of a single lesion, while 17, two, and three questionnaires described local injection of two, three, and four lesions, respectively. Two horses were treated twice for the same lesion. Overall, 72 horses (72\%) were reported to have either returned to or exceeded their previous level of work following local injection with the LAA: 18 horses at less than three months, 40 horses at between three and six months, and 14 horses at greater than six months. Ten horses $(10 \%)$ were reported to have returned to work but not perform to previous standards: two horses at less than three months, six horses at between three and six months, and two horses at greater than six months. Eighteen horses (18\%) were reported to have not returned to work as a result of the injury and showed no improvement. 
Table 1

Outcome by signalment of 100 horses with tendonitis/desmitis treated with a liquid amnion allograft.

$\begin{array}{ll}\begin{array}{l}\text { Returned to or } \\ \text { exceeded }\end{array} & \begin{array}{l}\text { Returned to work but } \\ \text { crevious not perform to } \\ \text { work }\end{array} \\ \text { previous standards }\end{array}$

No return to work as a result of the injury and no improvement

Age

$\begin{array}{llll}\leq 3 \text { years } & 4 & 0 & 3 \\ 4 \text { to } 10 \text { years } & 40 & 6 & 9 \\ \geq 11 \text { years } & 26 & 4 & 5 \\ \text { ND } & 2 & 0 & 1\end{array}$

Weight

$<500 \mathrm{~kg}$

8

3

2

$500-800 \mathrm{~kg}$

59

7

15

$>800 \mathrm{~kg}$

3

0

0

ND

2

0

1

Breed

AQHA/APHA

38

2

17

Arabian/1/2 Arabian

17

3

0

Warmblood

9

1

0

Thoroughbred

2

2

1

Other

4

2

0

ND

2

0

0

Sex

Stallion

4

0

0

Mare

31

4

6

Gelding

36

6

12

ND

1

0

0

Discipline

Western

Performance

ND - Not documented. TB - Thoroughbred 


\begin{tabular}{|c|c|c|c|}
\hline & $\begin{array}{l}\text { Returned to or } \\
\text { exceeded } \\
\text { previous level of } \\
\text { work }\end{array}$ & $\begin{array}{l}\text { Returned to work but } \\
\text { could not perform to } \\
\text { previous standards }\end{array}$ & $\begin{array}{l}\text { No return to work as a } \\
\text { result of the injury and } \\
\text { no improvement }\end{array}$ \\
\hline Barrel racing & 14 & 1 & 4 \\
\hline Roping & 5 & 1 & 4 \\
\hline Cutting & 4 & 0 & 3 \\
\hline Reining & 3 & 0 & 4 \\
\hline Not specified & 2 & 0 & 0 \\
\hline Show & 22 & 4 & 1 \\
\hline \multicolumn{4}{|l|}{ Sport } \\
\hline Racing - TB & 2 & 2 & 1 \\
\hline Racing - Other & 4 & 0 & 0 \\
\hline Hunter/jumper & 6 & 2 & 0 \\
\hline Dressage & 2 & 0 & 0 \\
\hline Not specified & 1 & 0 & 0 \\
\hline Other & 2 & 0 & 1 \\
\hline ND & 5 & 0 & 0 \\
\hline \multicolumn{4}{|l|}{ Location of Injury } \\
\hline Fore & 47 & 6 & 13 \\
\hline Hind & 25 & 4 & 5 \\
\hline \multicolumn{4}{|c|}{ Pre-Treatment Lameness Grade } \\
\hline 1 & 7 & 0 & 3 \\
\hline 2 & 27 & 1 & 2 \\
\hline 3 & 33 & 6 & 11 \\
\hline 4 & 5 & 3 & 2 \\
\hline \multicolumn{4}{|l|}{ Duration of Injury } \\
\hline$<6$ months & 37 & 4 & 10 \\
\hline 6 Months - 1 Year & 13 & 3 & 3 \\
\hline
\end{tabular}




\begin{tabular}{|c|c|c|c|}
\hline & $\begin{array}{l}\text { Returned to or } \\
\text { exceeded } \\
\text { previous level of } \\
\text { work }\end{array}$ & $\begin{array}{l}\text { Returned to work but } \\
\text { could not perform to } \\
\text { previous standards }\end{array}$ & $\begin{array}{l}\text { No return to work as a } \\
\text { result of the injury and } \\
\text { no improvement }\end{array}$ \\
\hline $1-2$ years & 6 & 1 & 3 \\
\hline$>2$ years & 10 & 1 & 0 \\
\hline ND & 6 & 1 & 2 \\
\hline ND - Not docur & Thoroughbred & & \\
\hline
\end{tabular}

The individual lesions were categorized based on their anatomic location and ability of the horse to return to work (Table 2). Horses associated with 94 of the 128 lesions were reported to have either returned to their previous level of work or exceeded their previous level of work: horses associated with 20 lesions at less than three months, 53 lesions at between three and six months, and 21 lesions at greater than six months. Horses associated with 13 of the 128 lesions were reported to have returned to work but not perform to previous standards: horses associated with two lesions at less than three months, six lesions at between three and six months, and five lesions at greater than six months. Horses associated with 21 of the 128 lesions were reported to have not returned to work as a result of the injury and showed no improvement. 
Table 2

Outcome of 128 tendonitis/desmitis lesions in 100 horses treated with a liquid amnion allograft.

$\begin{array}{ll}\begin{array}{l}\text { Returned to or } \\ \text { exceeded previous }\end{array} & \begin{array}{l}\text { Returned to work but could } \\ \text { not perform to previous } \\ \text { level of work }\end{array} \\ \text { standards }\end{array}$

Suspensory branch desmitis
All
$25(66 \%)$
$4(10 \%)$
$9(24 \%)$
Fore $\quad 16(73 \%)$
$0(0 \%)$
$6(27 \%)$
Hind $\quad 9(56 \%)$
$4(25 \%)$
$3(19 \%)$ tosult of the injury and no improvement

Proximal suspensory desmitis

$\begin{array}{llll}\text { All } & 11(73 \%) & 1(7 \%) & 3(20 \%) \\ \text { Fore } & 5(83 \%) & 1(17 \%) & 0(0 \%) \\ \text { Hind } & 6(67 \%) & 0(0 \%) & 3(33 \%)\end{array}$

DDF tendonitis - foot/pastern region

Fore $13(65 \%) \quad 3(16 \%) \quad 4(21 \%)$

DDF tendonitis - cannon region

$\begin{array}{llll}\text { All } & 10(100 \%) & 0(0 \%) & 0(0 \%) \\ \text { Fore } & 5(100 \%) & 0(0 \%) & 0(0 \%) \\ \text { Hind } & 5(100 \%) & 0(0 \%) & 0(0 \%)\end{array}$

SDF tendonitis

$\begin{array}{llll}\text { All } & 10(67 \%) & 2(13 \%) & 3(20 \%) \\ \text { Fore } & 8(62 \%) & 2(15 \%) & 3(23 \%) \\ \text { Hind } & 2(100 \%) & 0(0 \%) & 0(0 \%)\end{array}$

SDF-AL desmitis

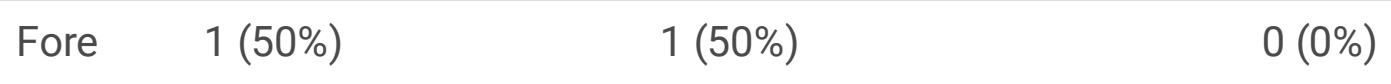

Collateral desmitis - coffin joint
Fore $\quad 9(90 \%)$
$1(10 \%)$
$0(0 \%)$

Collateral desmitis - Other
All
$3(60 \%)$
$1(20 \%)$
$1(20 \%)$

DDF - Deep digital flexor, SDF - Superficial digital flexor, AL - Accessory (check) ligament 


\begin{tabular}{|c|c|c|c|}
\hline & $\begin{array}{l}\text { Returned to or } \\
\text { exceeded previous } \\
\text { level of work }\end{array}$ & $\begin{array}{l}\text { Returned to work but could } \\
\text { not perform to previous } \\
\text { standards }\end{array}$ & $\begin{array}{l}\text { No return to work as a result } \\
\text { of the injury and no } \\
\text { improvement }\end{array}$ \\
\hline Fore & $2(67 \%)$ & $0(0 \%)$ & $1(33 \%)$ \\
\hline Hind & $1(50 \%)$ & $1(50 \%)$ & $0(0 \%)$ \\
\hline \multicolumn{4}{|c|}{ Straight sesamoidean desmitis } \\
\hline All & $6(86 \%)$ & $0(0 \%)$ & $1(14 \%)$ \\
\hline Fore & $4(80 \%)$ & $0(0 \%)$ & $1(20 \%)$ \\
\hline Hind & $2(100 \%)$ & $0(0 \%)$ & $0(0 \%)$ \\
\hline \multicolumn{4}{|c|}{ Oblique sesamoidean desmitis } \\
\hline All & $4(100 \%)$ & $0(0 \%)$ & $0(0 \%)$ \\
\hline Fore & $2(100 \%)$ & $0(0 \%)$ & $0(0 \%)$ \\
\hline Hind & $2(100 \%)$ & $0(0 \%)$ & $0(0 \%)$ \\
\hline $\begin{array}{l}\text { Patellar } \\
\text { desmitis }\end{array}$ & $2(100 \%)$ & $0(0 \%)$ & $0(0 \%)$ \\
\hline
\end{tabular}

On 92 of 100 questionnaires, the attending veterinarians reported they were satisfied with both the LAA and the response to therapy. Of these 92 questionnaires, 72 reported the horse to have returned to or exceeded their previous level of work, 10 reported the horse to have returned to work but not perform to previous standards, and 10 reported the horse to have not returned to work as a result of the injury and showed no improvement. Of the remaining eight questionnaires, six indicted that the attending veterinarian was not satisfied and reported the horse to have not returned to work as a result of the injury and showed no improvement. A satisfaction response was not documented on two questionnaires.

Questionnaires indicated that one or more adverse reactions occurred following 14 local LAA injections in 13 horses. Most reported adverse events were swelling (11) and/or redness (7) at the administration site. Four horses were reported to have an increase in lameness post-LAA injection, two of those being nonweight bearing. In three of the four cases, the increased lameness was noted within 24 hours of LAA treatment and resolved within 72 hours. In the fourth case, an increase in lameness was not noted until 14 days after injection and resolved within 48 hours.

\section{Discussion}

This multi-center clinical trial represents the first study to evaluate local injection of LAA for treatment of equine tendonitis and desmitis, and reports that $72 \%$ of treated horses returned to or exceeded their previous level of work after at least six months following treatment. In a previous report describing the 
outcome of 99 horses with tendon and ligament injuries treated with local injection of a PRP preparation, $81 \%$ of the horses returned to their previous use, $12 \%$ had clinical improvement but could not perform at the previous level, and $7 \%$ were classified as failures. ${ }^{21}$ Another controlled clinical study evaluating local injection of MSCs and PRP for the treatment of tendonitis and desmitis lesions in the cannon region of 23 horses reported 13 (57\%) to returning to racing within 15 months of treatment. ${ }^{22}$ Differences in the type and location of lesions as well as the breed or discipline of horses could account for the discrepancy between these success rates.

The most common lesion in the current study was categorized as suspensory branch desmitis (SBD), representing 38 of the $128(30 \%)$ lesions reported. A prior case series described 11 horses with 18 SBD lesions treated with a single intra-lesional injection of PRP reported that five horses (45\%) returned to their previous level of work within three months. ${ }^{23}$ In another study, 22 warmblood sport horses were treated for SBD using intra-lesional allogeneic umbilical cord-derived MSCs resulting in 15 (68\%) had returning to at least the same level of work after six months or more. ${ }^{24}$ In the current study, 25 of 38 (66\%) SBD lesions were associated with horses that either returned to or exceeded their previous level of work following local injection of LAA, a similar or more favorable rate than these prior reports. ${ }^{23,24}$

In the current study, proximal suspensory desmitis (PSD) lesions accounted for 15 (12\%) of the lesions, and $73 \%$ of those were associated with horses that either returned to or exceeded their previous level of work following local injection of LAA. In a previous study, 107 of 127 (84\%) horses with forelimb PSD and 108 of $144(75 \%)$ horses with hindlimb PSD were treated with a series of three peri-ligamentous injections of ACS, entered full training by 110 days from the initial injection, and had no recurrence of lameness after a month of training. ${ }^{25}$ In the current study, five of six (83\%) forelimb PSD lesions and six of nine (67\%) hindlimb PSD lesions were associated with horses that either returned to or exceeded their previous level of work, similar rates for forelimbs and slightly less favorable rates for hindlimb PSD compared to the previous study. ${ }^{25}$

Superficial digital flexor (SDF) tendonitis accounted for 15 (12\%) of the lesions in the current study. A case series of 22 racing Thoroughbreds with SDF tendonitis of varying severity reported that $64 \%$ of horses returned to racing following intra-lesional injection with PRP. ${ }^{26}$ In a controlled clinical trial of 20 horses with forelimb SDF tendonitis, 8 of $10(80 \%)$ horses treated with intra-lesional injection of PRP were performing at their previous level or higher 12 months post-injury while only 6 of $10(60 \%)$ control horses shared that success. ${ }^{27}$ A case series of 40 racing Thoroughbreds with SDF tendonitis treated with a series of four or five intra-lesional injections of insulin-like growth factor-type 1 reported that 21 of 34 (62\%) horses for which race data were available raced at least once after treatment. ${ }^{28}$ Additionally, 23 warmblood sport horses treated with intra-lesional injection of allogeneic umbilical cord-derived MSCs for SDF tendonitis resulted in 20 (87\%) of these horses returning to at least the same level of work at least six months following treatment. ${ }^{24}$ In the current study, $67 \%$ of the SDF tendonitis lesions treated with local injection of LAA were associated with horses that returned to or exceeded their previous level of work. The range of success rates reported in these previous reports and the current study may be 
explained by differences in number, breed and discipline of the horses as well as the location (fore vs hind, proximal vs. distal) and severity of the lesions.

In the current study, deep digital flexor (DDF) tendonitis lesions accounted for 25 of the $128(20 \%)$ lesions and were categorized anatomically as either cannon region or foot/pastern region. All 10 DDF tendonitis lesions in the cannon region as well as 13 of $20(65 \%)$ in the foot/pastern region were associated with horses returning to or exceeding their previous level of work. A study treating six warmblood sport horses with intra-lesional injection of allogeneic umbilical cord-derived MSCs for DDF tendonitis reported that four of these horses $(67 \%)$ returned to their previous level of work six or more months post-treatment, ${ }^{24}$ a rate similar to the current study. A search of the current literature could find no reports evaluating the use of regenerative modalities in the treatment of DDF tendonitis of the foot/pastern region exclusively. $A$ retrospective case study of 20 horses with 22 DDF tendonitis lesions treated with endoscopic debridement and/or navicular suspensory desmotomy reported that only nine (45\%) returned to pretreatment performance levels after six or more months. ${ }^{29}$ Thus, it would appear that local injection of LAA may be beneficial in the treatment of these lesion types.

The current study also describes treatment of collateral (15), distal sesamoidean (11), SDF accessory (2), and patellar (2) desmitis lesions with local injection of LAA. A search of the current literature found very few reports describing long term outcomes of horses diagnosed with these desmopathies with none evaluating the use of regenerative modalities for treatment. A study of the long-term outcome of 20 horses diagnosed with collateral desmitis of the distal interphalangeal joint and treated with a variety of modalities reports $12(60 \%)$ horses returning to and maintaining their previous level of exercise for at least three months while eight (40\%) were described to have a poor outcome. ${ }^{30}$ One horse in that report was treated with intra-lesional injection of a urinary bladder matrix powder but the outcome of that specific horses was not described. ${ }^{30}$ The current report includes 10 horses diagnosed with collateral desmitis of the distal interphalangeal joint with 9 of these $(90 \%)$ returning to or exceeding their previous level of work. A previous study described 27 horses diagnosed with desmitis of the oblique (18), straight (3), or both (6) sesamoidean ligaments (10 forelimb, 17 hindlimb) treated with various non-regenerative modalities in addition to rest and rehabilitation. Of the 21 available for follow-up, 16 (76\%) were competing at the same or better level of performance. ${ }^{31}$ Another study reported nine cases of straight sesamoidean desmitis ( 5 forelimb, 4 hindlimb) with six (67\%) able to return to their intended use following primarily rest and rehabilitation for six months although four were treated surgically. ${ }^{32}$ In the current report, six of seven (86\%) horses diagnosed with straight sesamoidean desmitis and all four horses diagnosed with oblique sesamoidean desmitis returned to or exceeded their previous level of work following local injection of LAA, rates more favorable than previously reported. In a prior report, six of eight $(75 \%)$ horses suffering from SDF accessory desmitis returned to their previous level of performance within six months following anti-inflammatory injection of the carpal sheath and rest. ${ }^{33}$ Both of the horses diagnosed with SDF accessory desmitis in the current study returned to or exceeded their previous level of work following local injection of with LAA. In a study of nine clinical cases of patellar desmitis, five were treated with rest and rehabilitation, three were treated surgically, and one was euthanized. ${ }^{34}$ of 
the nine, just one was able to return to its former level of competition. Both cases of patellar desmitis in the current report returned to or exceeded their previous level of work following local injection of with LAA. It is the authors' opinion that the results presented in the current study support the use of local injection of LAA for these desmopathies.

In the current study, the attending veterinarians reported local adverse reactions in $13 \%$ of horses following injection of LAA. Although most of the events were transient swelling and redness, there were four reports of increase in lameness. In all four cases, the increase in lameness was reported to have resolved within 72 hours with non-steroidal anti-inflammatory treatment. In a prior report, a local injection site reaction rate of $4.35 \%$ was reported for local injection of allogenic MSCs in 164 horses with 230 lesions, which included 208 tendon or ligament lesions. ${ }^{35}$ The disparity in local adverse reaction rate between this report ${ }^{35}$ and the current study could relate to the difference in study design or the regenerative product used. Additionally, transient local adverse reaction rates as high as $12 \%$ are reported following injection of sodium hyaluronate. ${ }^{36}$

The attending veterinarian reported satisfaction with the LAA product in 92 of 100 horses, indicating an overall positive experience. Interestingly, the attending veterinarian reported satisfaction in 10 horses that failed to show improvement following local injection of LAA. Reasons for this may be that improvement was not expected due to the severity of the lesion or satisfaction referred to the LAA product's availability and ease of administration.

Limitations of the current study include the non-blinded design and the lack of a control group. Also, the number of attending veterinarians likely introduced variability in patient selection and exact treatment methodologies (volume of LAA injected per lesion, LAA administration technique, etc.). Additionally, some of the specific lesion categories were low in numbers and may not represent an appropriate sample size, thus making interpretation difficult.

\section{Conclusions}

Results of this clinical trial indicate that local injection of LAA achieves comparable rates of return to previous level of work as other regenerative modalities such as MSCs, PRP and ACS in horses diagnosed with tendonitis or desmitis. However, blinded, placebo-controlled studies focusing on specific lesion types are indicated to more accurately evaluate the usefulness of local injection of LAA for the treatment of equine tendonitis or desmitis.

\section{Methods}

The design of the study was a non-blinded clinical trial. Experienced equine veterinarians at 14 hospitals (sites) were selected for participation in the study. The LAA was shipped frozen by the manufacturer to the sites with instructions to keep the product frozen at $-80^{\circ} \mathrm{C}$ until use to preserve the beneficial proteins. Each site was provided with a calibrated $-80^{\circ} \mathrm{C}$ portable freezer (Shuttle C Model ULT-25NE, Stirling 
Ultracold) to store the LAA when received. The LAA was provided in $1.5 \mathrm{~mL}$ and $3.0 \mathrm{~mL}$ volumes aseptically packaged in individual vials. Instructions for use directed the veterinarian to thaw the LAA at room temperature and administer it locally in or around the lesion using strict aseptic technique including aseptic preparation of the administration site and the use of sterile gloves and administration paraphernalia. The volume of LAA used to treat an individual lesion was left to the attending veterinarian's discretion.

Client-owned horses were selected for enrollment and subsequent treatment with LAA at the discretion of the attending veterinarian following examination, diagnosis and client education. Written informed client consent for treatment was obtained by the attending veterinarian prior to treatment. Criteria for inclusion in the study was defined as a horse displaying fore or hind limb lameness attributed to a specific diagnosis (lesion) of tendonitis or desmitis proven or supported by diagnostic anesthesia and/or imaging (ultrasound or magnetic resonance imaging) of the regional anatomy. Additionally, the identified lesion(s) must have been treated by local injection of LAA with follow-up information available for a period of at least six months. All horses remained in the care of the owners throughout the study period.

For each horse enrolled, a standardized questionnaire was completed by the attending veterinarian which included the date of LAA administration, LAA product code and serial number, horse identification and signalment, diagnosis(es), duration of injury/lameness, initial and re-evaluation lameness grade ${ }^{37}$, ability to return to work, adverse events, and product satisfaction (Additional file 1). The studied outcome measure was the ability of the horse to return to work following LAA treatment. This was categorized as either returning to or exceeding the horse's previous level of work, returning to work but not able to perform to the horse's previous standards, or inability to return to work as a result of the injury and showing no improvement. Following review of the completed questionnaires, information from those meeting the above criteria was compiled and those deemed not to have met the study criteria or those missing pertinent information (diagnosis, initial lameness grade, or ability to return to work) were excluded. If a horse was administered LAA for treatment of two or more separate lesions concurrently, each was considered a separate lesion.

\section{List Of Abbreviations}

ACS - autologous conditioned serum

DDF - deep digital flexor

LAA - liquid amnion allograft

MSC - mesenchymal stem cells

PRP - platelet rich plasma

PSD - proximal suspensory desmitis 
SBD - suspensory branch desmitis

SDF - superficial digital flexor

\section{Declarations}

Ethics approval and consent to participate: No human participants have been involved. No ethical approval was obtained because all patients had naturally occurring disease and all treatments were performed for the direct benefit of the patient. Following consultation about the study design, written informed client consent was obtained for treatment of all horses.

Consent for publication: Not applicable

Availability of data and materials: The data that supports the findings of this study are available upon request of the corresponding author. The data is not publicly available due to client/patient privacy restrictions.

Competing interests: MJS and BAH have consulting agreements with Equus Innovations. Their responsibilities are to serve as medical experts on issues pertaining to products, collaborate with personnel and external parties in the selection, construction and implementation of clinical trials to evaluate performance of products, participate in product design, development, and testing and engage with stakeholders on a peer-to-peer basis regarding product use, characteristics and potential for expanded clinical indications. Additionally, BAH is a minority shareholder in Equus innovations. HRD has no conflicts of interest to declare.

Funding: The liquid amnion allograft used in this study was provided to the sites for use in enrolled horses at a discounted cost by the manufacturer, Equus Innovations.

Authors' contributions: All authors (HRD, MJS, BAH) contributed to study design, study execution, data analysis and interpretation, and final approval of the submitted manuscript and have agreed both to be personally accountable for the author's own contributions and to ensure that questions related to the accuracy or integrity of any part of the work, even ones in which the author was not personally involved, are appropriately investigated, resolved, and the resolution documented in the literature. HRD and MJS wrote the manuscript.

Acknowledgements: The authors wound like to thank Drs. Josh Blyden, Jessica Bush, Nathan Canada, Jesse Clement, Alan Donnell, Tim Eastman, Reese Hand, Tommy Hays, Brad Hill, Cliff Honnas, Lauren Lamb, Shelby Matz, Garrett Metcalf, Krystle O'Cull, Cameron Stoudt, Andy Walker, Ty Wallis, and Chad Zubrod for their assistance enrolling horses and submitting completed questionnaires.

\section{References}

1. Dahlgren LA. Pathobiology of tendon and ligament injuries. Clin Tech Equine Pract. 2007;6:168-73. 
2. Denoix J-M. Functional anatomy of tendons and ligaments in the distal limbs (manus and pes). Vet Clin North Am Equine Pract. 1994;10:273-322.

3. Dowling BA, Dart AJ, Hodgson DR, Smith RKW. Superficial digital flexor tendonitis in the horse. Equine Vet J. 2000;32:369-78.

4. Ely ER, Avella CS, Price JS, Smith RKW, Wood JLN, Verheyen KLP. Descriptive epidemiology of fracture, tendon and suspensory ligament injuries in National Hunt racehorses in training. Equine Vet J. 2009;41:372-8.

5. Nixon AJ, Dahlgren LA, Haupt JL, Yeager AE, Ward DL. Effect of adipose-derived nucleated cell fractions on tendon repair in horses with collagenase-induced tendinitis. Am J Vet Res. 2008;69:92837.

6. O'Sullivan CB. Injuries of the flexor tendons: focus on the superficial digital flexor tendon. Clin Tech Equine Pract. 2007;6:189-97.

7. Smith RKW, Webbon PM. Harnessing the stem cell for the treatment of tendon injuries: heralding a new dawn? Br J Sports Med 2005;39:582-4.

8. Thorpe CT, Clegg PD, Birch HL. A review of tendon injury: Why is the equine superficial digital flexor tendon most at risk? Equine Vet J. 2010;42:174-80.

9. Durgam S, Stewart M. Cellular and molecular factors influencing tendon repair. Tissue Eng Part B: Rev. 2017;23:307-17.

10. Richardson LE, Dudhia J, Clegg PD, Smith R. Stem cells in veterinary medicine - attempts at regenerating equine tendon after injury. Trends Biotechnol. 2007;25:409-16.

11. Watkins JP, Auer JA, Gay S, Morgan SJ. Healing of surgically created defects in the equine superficial digital flexor tendon: collagen-type transformation and tissue morphologic reorganization. Am J Vet Res. 1985;46:2091-6.

12. Fortier LA, Smith RKW. Regenerative medicine for tendinous and ligamentous injuries of sport horses. Vet Clin North Am Equine Pract. 2008;24:191-201.

13. Lopez MJ, Jarazo J. State of the art: Stem cells in equine regenerative medicine. Equine Vet J. 2015;47:145-54.

14. Ortved KF. Regenerative medicine and rehabilitation for tendinous and ligamentous injuries in sport horses. Vet Clin North Am Equine Pract. 2018;34:359-73.

15. Geburek F, Lietzau M, Beineke A, Rohn K, Stadler PM. Effect of a single injection of autologous conditioned serum (ACS) on tendon healing in equine naturally occurring tendinopathies. Stem Cell Res Ther. 2015;6:1-14.

16. Romagnoli N, Rinnovati R, Ricciardi G, Lambertini C, Spinella G, Spadari A. Clinical evaluation of intralesional injection of platelet-rich plasma for the treatment of proximal suspensory ligament desmitis in horses. J Equine Vet Sci. 2015;35:141-6.

17. Schnabel LV, Boone L, Peroni JF. Regenerative medicine. In: Auer JA, Stick JA, Kümmerle JM, Prange T, editors. Equine Surgery. 5th ed. St Louis: W.B. Saunders; 2019. p. 104-22. 
18. Waselau M, Sutter WW, Genovese RL, Bertone AL. Intralesional injection of platelet-rich plasma followed by controlled exercise for treatment of midbody suspensory ligament desmitis in Standardbred racehorses. J Am Vet Med Assoc. 2008;232:1515-20.

19. Litwiniuk M, Grzela T. Amniotic membrane: New concepts for an old dressing. Wound Repair and Regen. 2014;22:451-6.

20. McCoy AM, Smith RL, Secor EJ, Roady PJ. Effects of 2 preparation methods and long-term storage on structural integrity and bacterial loads of equine amnion. Vet Surg. 2019;48:222-8.

21. Scala M, Lenarduzzi S, Spagnolo F, Trapasso M, Ottonello C, Muraglia A, Barla A, Squillario M, Strada $P$. Regenerative medicine for the treatment of teno-desmic injuries of the equine. a series of 150 horses treated with platelet-derived growth factors. In Vivo. 2014;28:1119-23.

22. Renzi S, Riccò S, Dotti S, Carlin S, Patruno M, Cinotti S, Ferrari M. Autologous bone marrow mesenchymal stromal cells for regeneration of injured equine ligaments and tendons: A clinical report. Res Vet Sci. 2013;95:272-7.

23. Castelijns G, Crawford A, Schaffer J, Ortolano GA, Beauregard T, Smith RKW. Evaluation of a filterprepared platelet concentrate for the treatment of suspensory branch injuries in horses. Vet Comp Orthop Traumatol. 2011;24:363-9.

24. Van Loon VJF, Scheffer CJW, Genn HJ, Hoogendoorn AC, Greve JW. Clinical follow-up of horses treated with allogeneic equine mesenchymal stem cells derived from umbilical cord blood for different tendon and ligament disorders. Vet Q. 2014;34:92-7.

25. Easter JL, Watts AE. How to select cases and use autologous conditioned serum to treat proximal suspensory desmitis. Proc Am Assoc Equine Pract. 2014;41:516-22.

26. Zuffova K, Krisova S, Zert Z. Platelet rich plasma treatment of superficial digital flexor tendon lesions in racing Thoroughbreds. Vet Med. 2013;58:230-9.

27. Geburek F, Gaus M, van Schie HTM, Rohn K, Stadler PM. Effect of intralesional platelet-rich plasma (PRP) treatment on clinical and ultrasonographic parameters in equine naturally occurring superficial digital flexor tendinopathies - a randomized prospective controlled clinical trial. BMC Vet Res. 2016;12:191.

28. Witte $T H$, Yeager AE, Nixon AJ. Intralesional injection of insulin-like growth factor-I for treatment of superficial digital flexor tendonitis in Thoroughbred racehorses: 40 cases (2000-2004). J Am Vet Med Assoc. 2011;239:992-7.

29. Smith MRW, Wright IM, Smith RKW. Endoscopic assessment and treatment of lesions of the deep digital flexor tendon in the navicular bursae of 20 lame horses. Equine Vet J. 2007;39:18-24.

30. Gutierrez-Nibeyro SD, White NA, Werpy NM, Tyrrell L, Allen KA, Sullins KE, Mitchell RD. Magnetic resonance imaging findings of desmopathy of the collateral ligaments of the equine distal interphalangeal joint. Vet Radiol Ultrasound. 2009;50:21-31.

31. Sampson SN, Schneider RK, Tucker RL, Gavin PR, Zubrod CJ, Ho CP. Magnetic resonance imaging features of oblique and straight distal sesamoidean desmitis in 27 horses. Vet Radiol Ultrasound. 2007;48:303-11. 
32. Schneider RK, Tucker RL, Habegger SR, Brown J, Leathers CW. Desmitis of the straight sesamoidean ligament in horses: 9 cases (1995-1997). J Am Vet Med Assoc. 2003;222:973-7.

33. Denoix JM, Guizien I, Perrot P, Bousseau B. Ultrasonographic diagnosis of the accessory ligament of the superficial digital flexor tendon (proximal check ligament) in 23 horses. Proc Am Assoc Equine Pract. 1995;41:142-3.

34. Dyson SJ. Normal ultrasonographic anatomy and injury of the patellar ligaments in the horse. Equine Vet J. 2002;34:258-64.

35. Ursini TL, Amelse LL, Elkhenany HA, et al. Retrospective analysis of local injection site adverse reactions associated with 230 allogenic administrations of bone marrow-derived mesenchymal stem cells in 164 horses. Equine Vet J. 2019;51:198-205.

36. Hyvisc [package insert]. St. Joseph, MO 64506 U.S.A.: Boehringer Ingelheim Vetmedica, Inc.; 2009.

37. AAEP Lameness Exams: Evaluating the Lame Horse. Available at https://aaep.org/horsehealth/lameness-exams-evaluating-lame-horse.

\section{Supplementary Files}

This is a list of supplementary files associated with this preprint. Click to download.

- ArriveChecklist8.16.2020.docx

- Supplementaryfile1.pdf 